\title{
Applying implicit knowledge for enterprise architectural transformation
}

\author{
Igor Petrov ${ }^{1, *}$, Tatyana Larinina $^{2}$ and Natalia Samosudova ${ }^{3}$ \\ ${ }^{1}$ Vyatka State University, 36, Moskovskaya str., 610000, Kirov, Russia \\ ${ }^{2}$ Vyatka State Agricultural Academy, 133, Oktyabrsky bvld., 610017, Kirov, Russia \\ ${ }^{3}$ Moscow State University of Civil Engineering, 26, Yaroslavskoye Shosse, 109377, Moscow, Russia
}

\begin{abstract}
The study describes a simulation model for the formalization of implicit knowledge about the team. The existing algorithms and methods of work to increase the amount of useful knowledge about the human capital of the organization do not allow obtaining knowledge about the development of the team and internal relationships. The effectiveness of architectural transformations directly depends on the quality of human capital management. The proposed model formalizes relations in the organization and proposes to form one of 4 strategies for personnel development, considering the individual characteristics of each of the employees. The article introduces the concepts of types of thinking and their connection to the life cycle of an organization. The study showed that the assessment of the organization's personnel composition reveals the hidden cause-effect relationships between the effectiveness of the team and the stages of the organization's life cycle.
\end{abstract}

\section{Introduction}

The competitiveness of a modern company directly depends on the degree of sustainability of enterprise architecture. The application of architectural patterns to strategic management is based on monitoring and continuous transformation [1-4]. Application of an architectural approach to strategic human resource management is discussed in [5-7]. Human resources are considered in terms of work, mental or physical activity. A normalized quantitative assessment of a person's abilities that are of value to a company is called a human resource. Applying human resources to strategic management requires the alignment of assessments for different levels of enterprise architecture design. One of the main assessments of a human resource is explicit and implicit knowledge. Other popular assessments are the level of leadership, creativity, thinking, stress resistance, communication, conflict.

The formalization of explicit knowledge and its assessment are considered in [8-10]. The more formalized knowledge in the company, the more significant the assessment of tacit knowledge becomes. It should be noted that for some areas of activity, tacit knowledge is the basis of the added value of the company, so it is not profitable for the staff to formalize it.

\footnotetext{
*Corresponding author: soft.rosko@mail.ru
} 
Implicit knowledge can be attributed to interpersonal mutual relations in a team. This kind of knowledge allows you to effectively manipulate staff motivation, create stable and long-term teams with minimal conflict. The complexity of existing approaches is the subjectivity of existing methods of forming assessments of interpersonal mutual relations.

The growth of a company leads to a non-linear increase in the number of relationships, so the application of knowledge about interpersonal relationships is difficult. The most typical scenario is to predict the degree of conflict of a person in a team.

The constant transformation of companies creates the need to take into account not only interpersonal relationships but also to assess the impact of the team on the development of personal qualities of personnel. The most typical scenario of emerging problems is a decrease in the level of strategic decisions made due to a decrease or increase in the level of stress. Another problem is the complexity of building staff into the team in the face of constant transformation of the company.

\section{Material and Methods}

We will combine the identified problems and use cases into the problem of the lack of formal assessments of the implicit knowledge of a person and the impossibility of embedding them into the existing methods of the architectural transformation of the company.

One of the existing approaches to the extraction of implicit knowledge is considered in [11]. Scenarios of human social behaviour and forms of thinking are distinguished as assessments. This approach is called socionics in popular literature [12-14].

To embed assessment data into the formats of architectural transformation, we will single out the following entities: position, position competencies, employee competencies, employee social environment. The proposed model is shown in Figure 1.

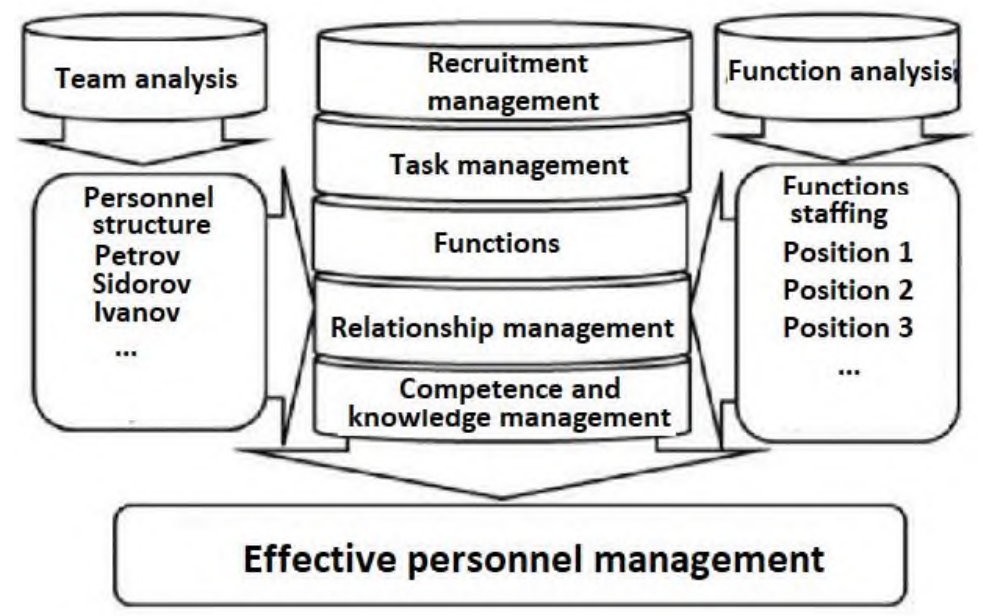

Fig. 1. Model of personnel management in the organization.

The position is understood as the social position of a person in the company by the organizational structure. Usually, together with the position, a set of competencies for the position held and a list of strategic decisions to be made are formed. There are 4 models of thinking in socionics, which are conventionally called: cause-effect thinking, dialecticalalgorithmic thinking, vortex-synergetic thinking and holographic thinking [15]. Different stages of company development require different types of company leadership. In the 
emergence of new products, the most significant is holographic thinking, at the stage of searching for values and forming a company, vortex-synergetic thinking, if support and sustainable growth are necessary, cause-effect thinking, and for the stage of improving and modernizing products, people with a dialectical-algorithmic type of thinking are needed.

The level of decisions made, assessments and logical judgments depend on the degree of competence in the given problem areas of the staff itself and is a function of explicit knowledge and experience.

The competencies of a position are a set of explicit requirements for the work performed by personnel. In most cases, this set of requirements is formal for the position and has a different distribution within the team. The presence of unformalized work in the team leads to staff overload, missed deadlines and a significant increase in the influence of the human factor on the company's performance [16]. The competencies of a position can be both a function of explicit and implicit knowledge.

An employee's competence is a set of innate and trainable skills, knowledge, experience and a way of thinking. The dataset of categories allows you to unambiguously correlate the employee with the position held. The presence of quantitative assessments allows you to highlight possible problem areas, expectations and possible real results of work. The most unpredictable function is staff experience. The described solution does not explicitly take into account the staff experience.

The social environment of the employee is the most important in the formation of the informal distribution of the competencies of the position. Therefore, it is necessary to take into account the employee's environment, his probabilistic and actual circle of contacts. The influence of the number of contacts on the nature and quality of work performed is different for each sociotype. The use of the socionic model allows discrediting the relationship according to typical scenarios of behaviour. Typical scenarios for the behaviour of mutual relations between sociotypes allow us to single out the informal redistribution of the competencies of positions in the team.

The entities specified above allow us to propose a simulation numerical model for team analysis, which is based on the correspondence between the position and the employee through the correlation of the described entity attributes. The result of modelling is both the formation and assessment of 4 strategies for personnel management in the company: the redistribution of positions. This strategy involves changing the social status of the position by the set of competencies that the employee performs. This strategy is typical for dynamically developing teams in which the social significance of the position, that is, the degree of centralization of management is very high.

In the case of an established team, in which traditions and cultural values prevail over formalized rules, a strategy for the redistribution of competencies is used. This strategy involves increasing the amount of work done by adding informal work that brings value to the team.

For companies in which it is necessary to collect personnel with unique experience or knowledge to formalize it in the knowledge management system, restructuring the team for a key employee is the most effective. In this case, the position, the competence of the position, and the social environment are selected taking into account the maximum comfort of the employee. At the same time, the total number of team tasks does not decrease. Efficiency is increased by specializing for a key employee.

In the case of creating a corporate culture, a necessary success factor is the formation of a well-coordinated team, therefore it is necessary to optimize the distribution of the competencies of the position by the competencies of the employee. In this case, the degree of comfort of the team is an important factor. [16-22]

Experimental confirmation of the described model of team optimization was investigated at companies of different stages of the life cycle and the size of the team. 


\section{Results}

Consider a beginner startup with 3 people. The typological map of the company is shown in Table 1.

Table 1. Typological map of service startup.

\begin{tabular}{|c|c|c|}
\hline Name & Position & Social Type \\
\hline Sidorov & Head of sales & Administrator \\
\hline Petrov & Director & Politician \\
\hline Ivanov & Sales manager & Analyst \\
\hline
\end{tabular}

The company has a service business with a famous product. Such a business is effectively run by a director with a cause and effect mindset. The main business improvements are in the field of sales since the head of sales has a dialectical-algorithmic type of thinking. It is in this area that the company's innovation and competitive advantage will be concentrated.

For the social environment, in such a company, the conflict in the relationship between the director and the sales manager is levelled through the head of sales, who has a more comfortable relationship with the director. At the same time, the tasks of external communications have been redistributed towards the director.

For large teams, one building typological maps are divided into levels of interaction and can be built for each position separately. An example of analyzing the comfort of team relationships is shown in Table 2.

Table 2. Example of analysis of the comfort of relationship.

\begin{tabular}{|c|c|c|c|c|c|}
\hline Comfortable & Num & Neutral & Num & Strenuous & Num \\
\hline Mirror & 3 & Customer & 5 & Conflict & 2 \\
\hline Dual & 5 & Constructor & 5 & SuperEgo & 1 \\
\hline Activation & 3 & Revision & 4 & Auditor & 4 \\
\hline Identity & 2 & Mirage & 2 & & \\
\hline Semi-dual & 3 & Business & 1 & & \\
\hline & & Related & 3 & & \\
\hline & & Antithesis & 1 & & \\
\hline & & Quasimodel & 1 & & $\mathbf{7}$ \\
\hline
\end{tabular}

The case shown in the figure is typical for an established team with a formed set of values. The presence of complex relationships in the team is neutralized through informal rules and corporate culture.

\section{Discussion}

In the theory of socionics, the nature of the relationship and the sociotype are constant. Identification of patterns of relationships allows us to conclude about a possible sociotype. Information about the sociotype makes it possible to conclude the type of thinking and psychological patterns of human behaviour.

This approach opens opportunities to improve the efficiency of managing the capabilities of each employee of the organization and to bring the functional responsibilities of the organization in line with the abilities. At the same time, it is possible to optimize the microclimate in a department or organization by modelling the mutual relations. The analysis of mutual relations allows, with the help of rotations and changes in personnel, to harmonize relations in the team. Also, understanding mutual relationships become the basis for tacit knowledge management and communication between employees, which is very 
important for Kaizen and the spiral of tacit and tacit knowledge management in the organization. The study of the staff of one of the departments of the university obtained the following results. There were considered 3 types of research, economic contract, and educational activities. A detailed examination of the activities revealed that the department most effectively carries out the educational process due to the dominant ethics. The weak side of the department is the presence of only one type of intuitive logic and one sensory logic, therefore there are problems in the quality of publications and the level of scientific activity. This practice of team analysis allows you to form management decisions that will consider current weaknesses. For example, the involvement of external scientists in the formation of the research agenda of the department and the formation of young personnel with a holographic or dialectical-algorithmic type of thinking.

\section{References}

1. D. Demitru, Procedia Manufacturing 46, 932-940 (2020)

2. R. Ansyori, Procedia Computer Science 135, $43-51$ (2018)

3. C. Azevedo, Information Systems 54, 235-262 (2015)

4. S.R. Mirsalari, Evaluation and Program Planning 83 (2020)

5. K. Löffler, Best Practice \& Research Clinical Anaesthesiology 32, 47-55 (2018)

6. M.J. Hutt, Journal of Dairy Science 76, 2069-2079 (1993)

7. A.R. Burden, Anesthesiology Clinics (to be published)

8. K. Anjaria, Expert Systems with Applications 157, 493-497 (2020)

9. S.R. Oktari, International Journal of Disaster Risk Reduction 51 (2020)

10. A. Mottaeva, As. Mottaeva, EMMFT 2019, AISC 1258, 506-517 (2021) https://doi.org/10.1007/978-3-030-57450-5_44

11. V. Gulenko, Teamwork management (REPAL, 1995)

12. V. Gulenko, Humanitarian socionics (Black squirrel, 2009)

13. J. Jankowski, The 16 Personality Types in a Nutshell (LOGOS MEDIA, 2016)

14. K. Pietrak, Cognitive Systems Research 47, 1-11 (2018)

15. V. Gulenko, Types of people and business. How 16 types of personality determine your success at work (AST, 2001)

16. E. Ganebnykh, O. Lezhnina, T. Zhilkina, E3S Web of conferences 164, 10033 (2020)

17. Chechevichkin, V.N., Vatin, N.I. Magazine of Civil Engineering. 2014. 50(6). Pp. 6774. DOI:10.5862/MCE.50.7.

18. Kovačič, B., Kamnik, R., Pustovgar, A., Vatin, N. Procedia Engineering. 2016. 165. Pp. 918-925. DOI:10.1016/j.proeng.2016.11.801.

19. Ognjenovic, S., Donceva, R., Vatin, N. Procedia Engineering. 2015. 117(1). Pp. $544-$ 550. DOI:10.1016/j.proeng.2015.08.210.

20. Ognjenovic, S., Donceva, R., Vatin, N. Procedia Engineering. 2015. 117(1). Pp. 551558. DOI:10.1016/j.proeng.2015.08.212.

21. Ognjenovic, S., Ristov, R., Vatin, N. Procedia Engineering. 2015. 117(1). Pp. 568-573. DOI:10.1016/j.proeng.2015.08.215.

22. Ognjenović, S., Zafirovski, Z., Vatin, N. Procedia Engineering. 2015. 117(1). Pp. 574579. DOI:10.1016/j.proeng.2015.08.216.

23. G. Kozlov, M. Pushkarev, V. Mokhna E3S Web of Conferences 135, 01052 (2019) doi:10.1051/e3sconf/201913501052 